Article

\title{
The NEWA Ferry Lidar Experiment: Measuring Mesoscale Winds in the Southern Baltic Sea
}

\author{
Julia Gottschall $1, * \mathbb{C}$, Eleonora Catalano ${ }^{2}$, Martin Dörenkämper ${ }^{3}\left(\mathbb{D}\right.$ and Björn Witha ${ }^{4}$ \\ 1 Fraunhofer Institute for Wind Energy Systems IWES, 27572 Bremerhaven, Germany \\ 2 RES Australia, Sydney, NSW 2067, Australia; ele.catalano@gmail.com \\ 3 Fraunhofer Institute for Wind Energy Systems IWES, 26129 Oldenburg, Germany; \\ martin.doerenkaemper@iwes.fraunhofer.de \\ 4 ForWind, Institute of Physics, University of Oldenburg, 26129 Oldenburg, Germany; bjoern.witha@uol.de \\ * Correspondence: julia.gottschall@iwes.fraunhofer.de; Tel.: +49-471-14290-354
}

Received: 31 August 2018; Accepted: 6 October 2018; Published: 12 October 2018

check for updates

\begin{abstract}
This article presents the Ferry Lidar Experiment, which is one of the NEWA Experiments, a set of unique flow experiments conducted as part of the New European Wind Atlas (NEWA) project. These experiments have been prepared and conducted to create adequate datasets for mesoscale and microscale model validation. For the Ferry Lidar Experiment a Doppler lidar instrument was placed on a ferry connecting Kiel and Klaipeda in the Southern Baltic Sea from February to June 2017. A comprehensive set of all relevant motions was recorded together with the lidar data and processed in order to obtain and provide corrected wind time series. Due to the existence of the motion effects, the obtained data are essentially different from typical on-site data used for wind resource assessments in the wind industry. First comparisons show that they can be well related to mapped wind trajectories from the output of a numerical weather prediction model showing a reasonable correlation. More detailed validation studies are planned for the future.
\end{abstract}

Keywords: Doppler lidar; NWP model; mesoscale; Floating Lidar System (FLS), wind resource assessment; wind atlas

\section{Introduction}

The consortium of the New European Wind Atlas (NEWA [1]) project is currently creating a later publicly available and freely accessible wind atlas covering essentially the countries of the European Union and Turkey. The coverage further includes offshore areas up to $100 \mathrm{~km}$ from shore and the complete North and Baltic Sea. The basis of the atlas is a model chain, also developed within the project, comprising mesoscale and microscale flow models that are run to generate the wind time series and statistics making up the atlas. Mesoscale time series data, which represent the largest part of the atlas, will be available with a spatial resolution of $3 \mathrm{~km} \times 3 \mathrm{~km}$ and for a length of 30 years. The microscale resolution will be finer than $100 \mathrm{~m} \times 100 \mathrm{~m}$, but here only limited statistics will be provided. The third outcome of the project, besides the wind atlas and model chain, is an experimental database comprising the data from a number of quite unique flow experiments that have been conducted within the project.

The NEWA experiments vary not only in their locations but also in the assessed types of terrains and associated flow phenomena, their durations, and the level and complexity of involved equipment and resulting data volume [2]. Common to all experiments within NEWA is the application of Doppler lidar technology to supplement, and in some cases also completely replace, meteorological towers. This is not by chance, but indicates the breakthrough of a technology that has been continuously developed further for the wind industry within the last 10-15 years [3]. 
The sites of the NEWA experiments are distributed over the coverage of the later wind atlas (see Figure 1). It is important to emphasize that the experimental data are not integrated in the wind atlas. Instead of supplementing the model data, they are used to test and validate the involved models in dedicated benchmark studies. Each experiment has been defined with a specific focus [2], including a double ridge as in the Perdigao experiment (Portugal) [4], a complex steep terrain with a complex mesoscale flow in Alaiz (Spain), a flow over forested rolling hills in Hornamossen (Sweden), a single forested hill near Kassel (Germany), or a near-shore wind flow in RUNE (Denmark) [5].

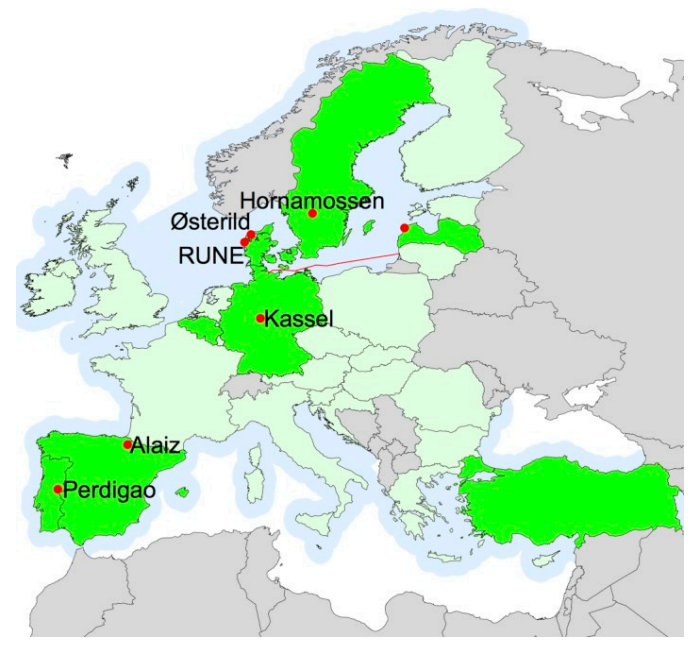

Figure 1. Minimum coverage of the New European Wind Atlas and sites of experiments. The minimum onshore coverage is shown in light green, the NEWA partner countries in a darker lime-green, offshore coverage in light blue, and experimental sites in red. The red line marks the route in the Ferry Lidar Experiment. (Graphic reproduced from Reference [2]).

The Ferry Lidar Experiment is the only offshore experiment within NEWA. Its name originates from its setup: a vertically scanning Doppler lidar is placed on a ferry boat to measure the wind along the ferry route, covering several hundreds of kilometers within one day and travelling back and forth for a period of several months. This rather simple setup is designed for studying mesoscale effects that are, in particular, far-offshore pre-dominant. For distances greater than $30 \mathrm{~km}$ from shore and at heights relevant for wind energy exploitation (i.e., greater than about $50 \mathrm{~m}$ ) microscale effects due to e.g., breaking sea waves do not play an important role [6]. Comparisons with data of meteorological (met) masts show that mesoscale models are capable of resolving the most important features of the marine atmospheric boundary layer and compare well with the in-situ measurements of a mast $[7,8]$. In this sense, it is common practice to validate and verify the data simulated with a mesoscale model (as, e.g., the known Numerical Weather Prediction (NWP) models) against data from offshore met masts [9]. In most cases, this is a fair comparison, just because of the absence of relevant microscale terrain effects impacting the mast measurements for the height ranges of interest. It has to be kept in mind, however, that an NWP data point is representative for an area of several square kilometers and not just a single spot; this may lead to some smoothing in the simulated data in comparison to spot-like mast measurements. As a second discrepancy, NWP models typically do not give averaged data representative of a certain time interval but instead instantaneous values, e.g., every 10 or $30 \mathrm{~min}$.

In a similar context as in the NEWA project, mesoscale model data were correlated with the measurement data, not just from one offshore met mast but several of those and a number of vertically profiling lidar devices installed on offshore platforms within the NORSEWInD project [10]. The activities within this project proved the usefulness of Doppler lidar technology for assessing offshore wind profiles provided a sufficient data availability is obtained. Like NWP models, the nowadays fully commercially available lidar devices can provide wind velocity data at a number of height levels more or less at the same point in time. This allows a direct assessment of the wind profile 
for up to several hundreds of meters, with the range depending on the explicit device specifications. With the Ferry Lidar Experiment, the concept of spatially distributed wind profile measurements is further developed. The profiling instrument moves with the ship and covers a distance that is comparable to a typical mesoscale dimension.

The article pursues the following three objectives:

- $\quad$ the ship lidar technology applied in the NEWA Ferry Lidar Experiment is to be introduced;

- the data produced by applying this technology is to be described in detail, such that the generated dataset can be used in future studies;

- $\quad$ and finally, a first comparison of the Ferry Lidar data to mesoscale model data is to be presented and discussed.

Approaching these objectives in the suggested order, the article is structured as follows. Following this introductory section, the ship lidar technology is presented in Section 2. The Ferry Lidar campaign within the NEWA project and the processed dataset from this campaign are described in Sections 3 and 4, respectively. In Section 5, we show an initial comparison between the recorded measurements and simulated data using an NWP model. An outlook in Section 6 and the conclusions in Section 7 complete the article.

\section{Ship Lidar Technology}

The Ship Lidar System applied for the NEWA Ferry Lidar Experiment has been developed by Fraunhofer IWES since 2009, and is an integrated system comprising the following components:

- a vertically profiling Doppler lidar device of the type Windcube v2 by the manufacturer Leosphere, (Orsay, France) which is the primary measurement sensor, capturing the wind velocity at up to 12 height levels above the instrument;

- a combination of an xSens MTi-G (Enschede, Netherlands) attitude and heading reference sensor (AHRS) and a Trimble SPS361 satellite compass (Sunnyvale, CA, USA), used to record high-resolution motion information that is required to correct the lidar wind data;

- a weather station collecting atmospheric data including air temperature, air pressure, and relative humidity and precipitation, complementing the dataset.

All data are collected and synchronized on a measurement computer. The Windcube v2 lidar device has a sampling resolution of about $0.7 \mathrm{~s}$ per line-of-sight (LoS) measurement and measures successively at four azimuthal positions along a cone with a half-opening angle of $28^{\circ}$ followed by a vertical beam. From these five measurements the wind velocity vector is reconstructed and updated after each new LoS measurement, resulting in a measurement frequency of about $1.4 \mathrm{~Hz}$. Further information on the ship lidar technology and its components can be found in Reference [11]. Figure 2 shows a typical installation of the system on deck of a medium-size vessel.

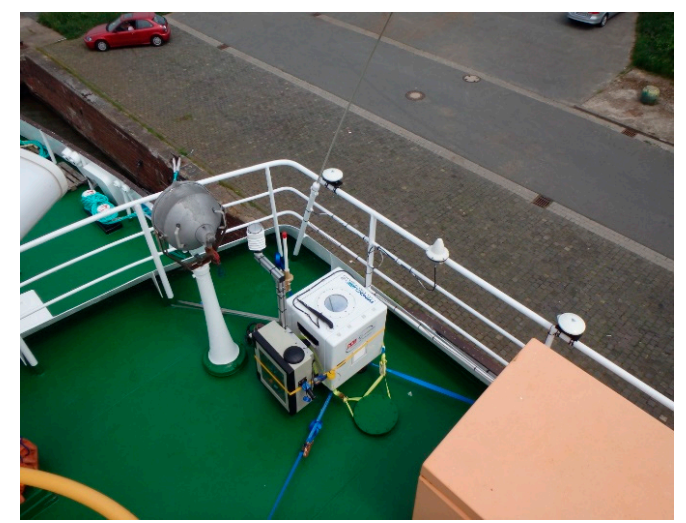

Figure 2. Installation of ship lidar System on deck of a medium-size vessel - C Fraunhofer IWES. 
An indispensable element of the ship lidar technology is the motion correction algorithm combining recorded lidar and motion data in order to provide motion-corrected wind data. The algorithm applies the basic principles outlined in Reference [12] and referred to in, e.g., Reference [13]; the recorded wind velocity vector is corrected for the translational velocity of the vessel and the involved platform rotations (including the heading of the ship as well as roll and pitch), respectively, according to

$$
V_{\text {true }}=T V_{\text {obs }}+\Omega \times T M+V_{\mathrm{CM}}
$$

where $V_{\text {true }}$ is the desired wind velocity vector in the reference coordinate system, $V_{\text {obs }}$ is the measured wind velocity vector in the platform frame of reference, $T$ is the coordinate transformation matrix for a rotation of the platform frame coordinate system to the reference coordinates, $\Omega$ is the angular velocity vector of the platform coordinate system, $M$ is the position vector of the platform coordinate system, and finally $V_{\mathrm{CM}}$ is the translational velocity vector at the center of motion of the platform with respect to a fixed coordinate system.

For the present configuration of the Fraunhofer IWES Ship Lidar System, a simplified motion correction was applied, where the vessel tilting was essentially ignored due to a negligible impact on the results. This modification was justified in a dedicated verification campaign, in which the system was tested under representative conditions against the fixed reference measurements of the FINO1 met mast in the German North Sea (for further details, see Reference [11]). The results confirm that the ship motions indeed affect the high-frequency data of the lidar but that these effects are averaged out when deriving the 10-min mean values; 10-min averaged lidar and reference data agree within $\pm 0.5 \mathrm{~m} / \mathrm{s}$ in a distance of up to about $1.5 \mathrm{~km}$ and show a reasonable correlation with a coefficient of determination $\left(\mathrm{R}^{2}\right)$ for a linear fit of 0.99 . How the motion correction acts on the data of the NEWA Ferry Lidar Experiment is shown in detail in Section 5.

The ship lidar technology should be further seen in the context of the floating lidar technology, a technology that has gained some attention within the offshore wind industry in the past decade (cf. Reference [14]). Floating Lidar Systems (FLSs), referring to a more or less stationary floating platform or buoy equipped with a commercial wind lidar device, particularly show economic benefits in an offshore wind resource assessment when compared to the state-of-the-art met masts, which as a standard, are used for the same application. An FLS can provide wind data of comparable quality as met masts but at considerably lower costs. A ship lidar cannot have the same purpose as a buoy-based measurement system since the movement of the ship has an essential impact on the obtained data, implying a non-stationarity, even if the local motions are compensated quite efficiently. Nonetheless, the development of the one technology can and has benefitted from the other. Also the motion effects on the measurements of an FLS can be described by Equation (1), though with another order of the most relevant motion impacts; while both for FLS and ship lidar heading information is most relevant to correct the wind direction data, the ship lidar wind speed data are essentially affected by the ship's translatory motions, the data of the FLS on the contrary by the tilting at a stationary position.

\section{Ferry Lidar Campaign within NEWA}

The NEWA Ferry Lidar Experiment started on 7 February 2017, and ended after four months of measurements on 8 June 2017. During this period, the Fraunhofer IWES Ship Lidar System was installed on the vessel Victoria Seaways, which belongs to the DFDS Seaways Group and operates on the route from Kiel, Germany, to Klaipeda, Lithuania, in the Southern Baltic Sea. One trip takes about $20 \mathrm{~h}$, and the vessel spends about $4 \mathrm{~h}$ in the harbor each time. Figure 3 shows the average route of the ferry; only small deviations from this route were observed during the period of the campaign. 


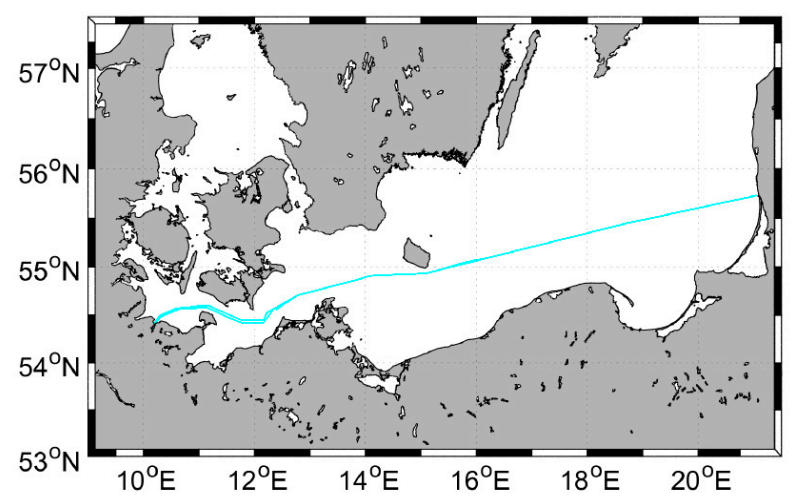

Figure 3. Route of Victoria Seaways, on which the ship lidar system was installed, from Kiel to Klaipeda in the Southern Baltic Sea (reproduced from Reference [15]).

The Victoria Seaways is a so-called ro-ro (for roll-on/roll-off) ship, designed to carry wheeled cargo, and has a passenger capacity of 600 persons. The vessel has an overall length of $199.14 \mathrm{~m}$ and a maximum velocity of 23.5 knots. The ship lidar system was installed on Deck 8, which is about $25 \mathrm{~m}$ above sea level (asl). Taking this offset into account, the resulting measurement heights of the lidar have been $65 \mathrm{~m}, 75 \mathrm{~m}, 90 \mathrm{~m}, 100 \mathrm{~m}, 110 \mathrm{~m}, 130 \mathrm{~m}, 150 \mathrm{~m}, 175 \mathrm{~m}, 200 \mathrm{~m}, 225 \mathrm{~m}, 250 \mathrm{~m}$, and $275 \mathrm{~m}$ asl. Figure 4 shows a photograph of the vessel while it is in the harbor and of the installation of the ship lidar system.

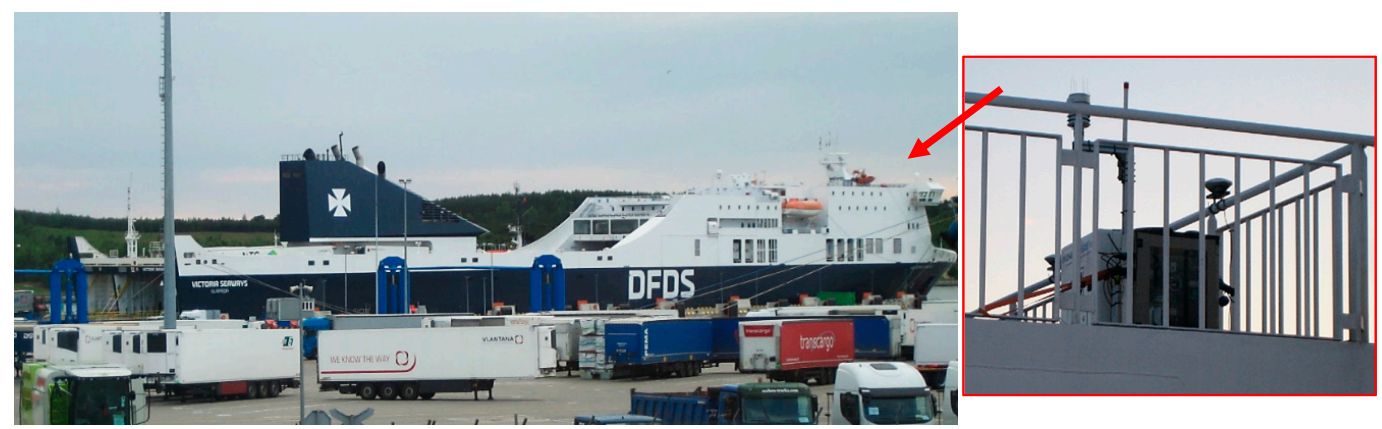

Figure 4. Ship lidar installation on Victoria Seaways-C Fraunhofer IWES.

Figure 5 shows exemplary trajectories of the recorded and processed wind data (10-min averages) from the ship lidar system in the NEWA Ferry Lidar Experiment. This example covers four days-25-28 February 2017- of the (in total) four months of data. The plot on the left side shows the path of the system within these four days. The ferry was in the harbor four times (twice in Kiel and twice in Klaipeda) during this period, which is clearly visible when comparing uncorrected and corrected wind data (see the right plots in Figure 5), and the periods where the time series of corrected and uncorrected wind speed overlap. For the uncorrected (raw) wind data, the effects of the ship's motions influencing the lidar measurements essentially appeared as offsets in wind speed (negative or positive, depending on the heading of the ship relative to the prevailing wind direction) and direction (depending on the heading of the ship with respect to true North). 

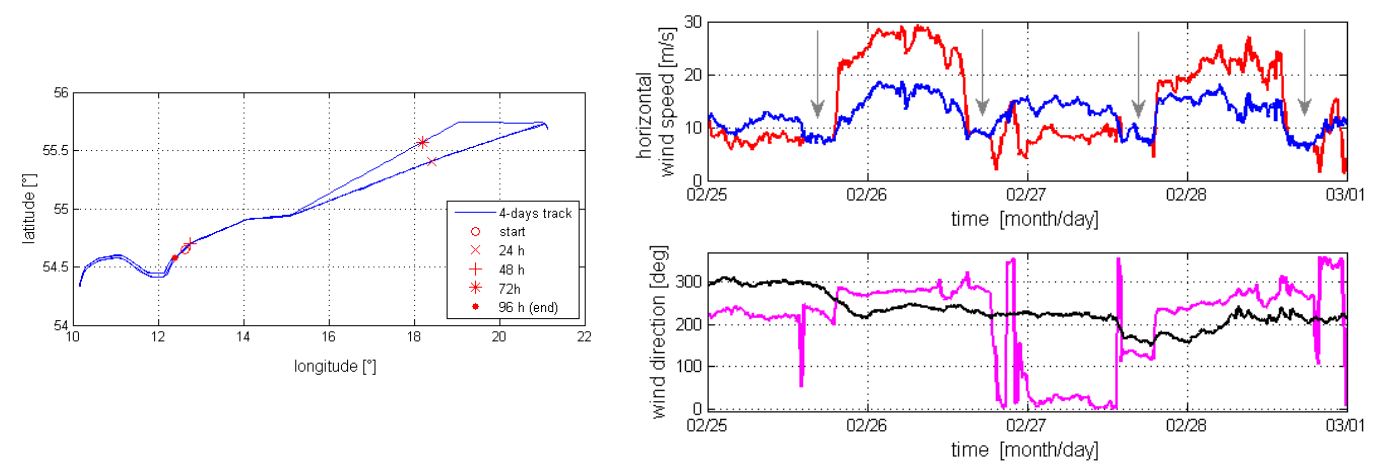

Figure 5. Four days of wind measurements from the ship lidar system: (left) path of Victoria Seaways in geo-coordinates, symbols show the position after 1, 2, 3, and 4 days; (right) corrected [blue/black] and uncorrected [red/pink] time series of horizontal wind speed [top] and direction [bottom] for $100 \mathrm{~m}$ measurement height. Periods where the ferry was in the harbor and therefore not moving are shown with the gray arrows.

\section{Processed Dataset}

The processed dataset comprises the corrected time series of horizontal wind speed and direction for the 12 measurement heights together with an availability measure for each data value. This measure represents the percentage of valid data in a 10-min interval where validity was defined on the basis of the respective carrier-to-noise ratio (CNR) value output by the lidar device and the availability of the motion data required to correct the lidar measurements. As a CNR threshold, we have used the value of $-23 \mathrm{~dB}$, which was pre-set and recommended by the manufacturer. High-frequency data, defined by one LoS measurement, that have a CNR value below this threshold were ignored for the derivation of the 10-min average.

Additionally, the position data of the ship-in terms of mean, minimum and maximum longitude (lon)/latitude (lat) coordinates, plus the distance between the minimum and maximum-were saved, along with the timestamp of the data vector. Figure 6 gives an impression of the processed data; the plot covers the same time span as in Figure 5 but this time shows the whole (corrected) wind speed and direction profiles instead of only a single time series. Note that the purpose of the plots was not to show and identify the single trajectories at the individual height levels, but rather to underline the profile information provided by the data. The occurrence of different atmospheric stability cases, represented by different wind shear and veer that is defined as wind speed and direction deviations with height, is clearly visible in this presentation. The magnitude of the vertical wind shear is correlated to the atmospheric stratification (e.g., References [16,17]). Periods with little or no wind shear (e.g., during most of February 25) indicate neutral or unstable stratification, while periods with a strong wind shear of up to $7 \mathrm{~m} / \mathrm{s}$ between 65 and $275 \mathrm{~m}$ height (e.g., during most of February 26) indicate stable stratification. Thus, the vertical change of the wind speed with height is an indicator of the presence of different atmospheric stabilities that are mainly caused by air-sea temperature differences. 

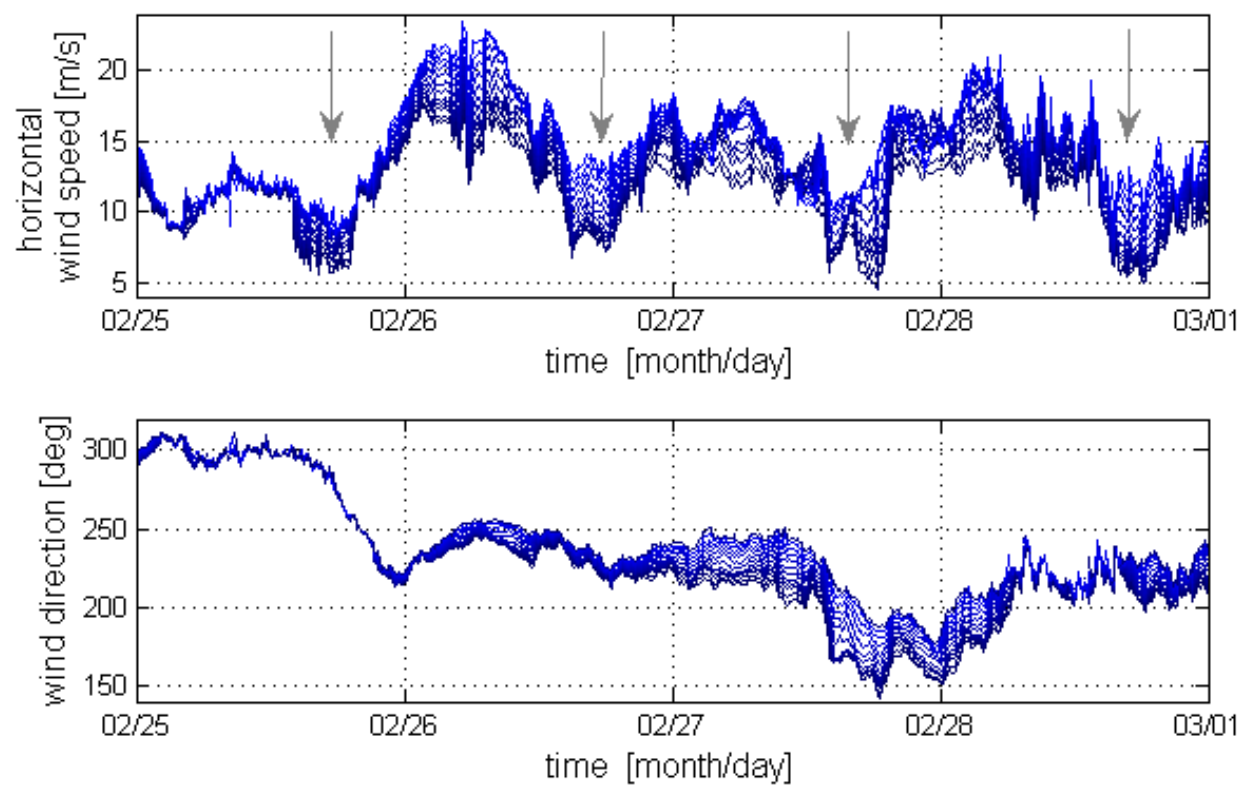

Figure 6. Processed horizontal wind speed and direction for the 12 measurement heights from $65 \mathrm{~m}$ to $275 \mathrm{~m}$ (darker colors for lower measurement heights). Periods where the ferry was in the harbor are again marked with the gray arrows.

Based on the derived availability measures for the individual 10-min averages, overall and monthly averages for the 12 measurement heights were evaluated (see Table 1). For this, it was additionally assumed that the 10 -min availability must be equal to $80 \%$ or greater for a measured data point to be valid. This value is a typical threshold for a wind resource assessment. The so assessed availability of the corrected lidar time series was well above $90 \%$ for the seven lower measurement heights up to $150 \mathrm{~m}$ and only decreased for the upper heights.

Table 1. Data availability of processed wind time series per measurement height and month.

\begin{tabular}{|c|c|c|c|c|c|c|c|c|c|c|c|c|}
\hline \multirow{2}{*}{ Month } & \multicolumn{12}{|c|}{ Availability per Measurement Height [\%] } \\
\hline & $65 \mathrm{~m}$ & $75 \mathrm{~m}$ & $90 \mathrm{~m}$ & $100 \mathrm{~m}$ & $110 \mathrm{~m}$ & $130 \mathrm{~m}$ & $150 \mathrm{~m}$ & $175 \mathrm{~m}$ & $200 \mathrm{~m}$ & $225 \mathrm{~m}$ & $250 \mathrm{~m}$ & $275 \mathrm{~m}$ \\
\hline February 2017 & 98 & 98 & 97 & 96 & 95 & 94 & 92 & 88 & 82 & 70 & 59 & 50 \\
\hline March 2017 & 97 & 97 & 98 & 97 & 97 & 95 & 93 & 90 & 83 & 75 & 64 & 51 \\
\hline April 2017 & 95 & 96 & 96 & 95 & 95 & 94 & 92 & 87 & 71 & 59 & 48 & 39 \\
\hline May 2017 & 95 & 95 & 96 & 96 & 96 & 95 & 93 & 88 & 75 & 60 & 44 & 30 \\
\hline June 2017 & 92 & 94 & 96 & 96 & 96 & 95 & 93 & 85 & 75 & 60 & 46 & 35 \\
\hline Total & 96 & 96 & 96 & 96 & 96 & 94 & 92 & 88 & 77 & 66 & 53 & 42 \\
\hline
\end{tabular}

\subsection{Low-Level Jet Information as Part of the NEWA Ferry Lidar Dataset}

The processing of the data from the NEWA Ferry Lidar Experiment was complemented with the derivation of essential low-level jet (LLJ) information. Following the definition of Baas et al. [18], an LLJ is defined at the lowest (local) maximum of the wind speed profile that is at least $2 \mathrm{~m} / \mathrm{s}$ and $25 \%$ faster than the next minimum above. Note that this definition includes the upper and lower edge of the profile defined by the measurement range of the lidar instrument. The LLJ information in the dataset includes the horizontal wind speed and height of the identified profile maximum, the position of the measurement (longitude/latitude coordinates), and the timestamp.

Figure 7 (left plot) shows the wind profiles with LLJs found for the 4-day period already presented in Figure 6. The wind speed maxima appear for measurement heights between $100 \mathrm{~m}$ and $175 \mathrm{~m}$, and all on 27 February 2017. The right plots of Figure 7 show all LLJ events found for the month of February (in total 20) with their geo-coordinates in comparison with those found for the month of May 
(in total 392). This initial comparison indicates that considerably more LLJ events were observed in the spring month than in a comparable period in winter, including a relevant number of wind-speed maxima at the lower limit of the profile range (cf. the color differentiation in Figure 7). This simple observation can be explained by the positive air-sea temperature difference that is typically largest in spring when the water body with its significantly higher heat capacity is still cold while the land at the coastlines typically already heats up. Offshore-oriented winds and the associated step change in the surface roughness can then lead to the development of LLJs. This process is well known (e.g., Reference [19]) and due to the cold waters in late spring very common for the Baltic Sea (e.g., Reference [20]).
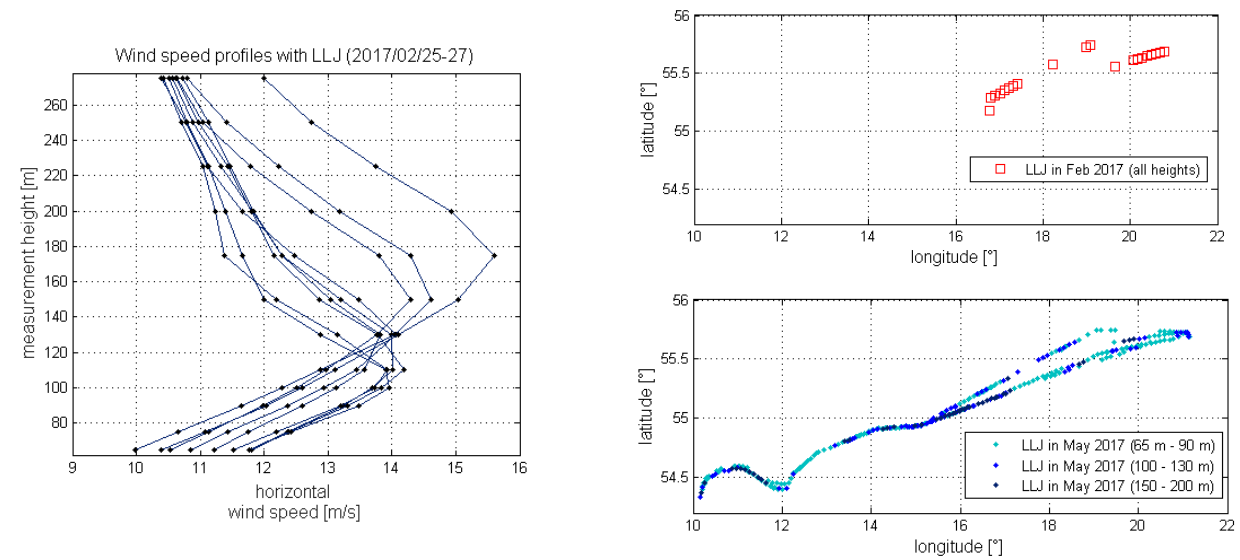

Figure 7. LLJ events observed in the NEWA Ferry Lidar Experiment: (left) vertical wind profiles for the period 25-27 February 2017; (right) events as markers on the ferry's route with latitude/longitude coordinates, where the top plot is for the month of February and the bottom plot for June in comparison.

\subsection{Uncertainty Estimation for Ship Lidar Data}

Generally, there are different ways to assess the uncertainty of (wind speed) measurements. In terms of metrology, and to trace back the uncertainty to available standards, a verification or calibration with respect to a suitable reference measurement is required. This principle is also followed in Reference [21] outlining the procedure of how to verify a ground-based vertically profiling Doppler lidar (or more general remote-sensing) instrument for applications in the wind industry. For a ship lidar system, such a verification test can only be realized under high effort, if at all. An attempt was undertaken in Reference [11] with the outcome referred to in Section 2. This result could be used to estimate a verification uncertainty component as one of the most relevant parts of the ship lidar measurement uncertainty. However, in the present case, we believe that, first, the dataset of the verification test was not big enough to derive robust results, and second, the ship lidar configuration in the verification may not have been similar enough to that in the final application; in particular, different types of vessels were used with different motion patterns.

Furthermore, the spatial aspect of the ship lidar measurements needs to be taken into account; the ship lidar measurements are not representative for a single spot in space as, e.g., the measurements of a met mast. The spatial variability of the measurements within the spanned 10-min interval are to be considered just as the temporal variations. This aspect becomes relevant when comparing the ship lidar data with other more "spatial" data (see Section 5). In this sense, we do not think that we could have assigned a single uncertainty figure to the ship lidar data, but rather include uncertainty considerations in the discussion of the data quality and precision in relation to reference datasets.

In this respect, it should also be paid attention to that since the ferry takes one trip per day with recurring departure and arrival times, there was a strong correlation between the location of the ferry, and therefore also the measurements, and time-of-day. 
Uncertainty components that could be well estimated are the uncertainties of the input data to the motion correction (i.e., heading and velocity of the ship) and their direct impact on the corrected wind estimates. But since the applied motion measurements were very precise, this contribution was assumed to be negligible in the presented context.

\section{Comparison with Mesoscale Model Data}

For the measurements in the Ferry Lidar Experiment, the ship lidar system had traversed distances of up to $6 \mathrm{~km}$ in one 10-min interval. This distance corresponds to the mesoscale in meteorological observations [22], which suggests relating the ship lidar measurements to the output data of an NWP model having a similar scale. A corresponding initial comparison of the ship lidar measurements with mesoscale model data is presented in this section.

We have used the same model which is used to generate the wind atlas within the NEWA project, namely the Weather Research and Forecasting Model (WRF) [23]. In detail, we used an offshore optimized setup (similar to the setup used in Reference [24]) that was intensively tested in a case study phase for the Wind Atlas generation. Figure 8 shows the model domains centered around the Southern Baltic Sea. WRF time series were generated with a temporal resolution of $30 \mathrm{~min}$ and on a $3 \mathrm{~km} \times 3 \mathrm{~km}$ grid; further details of the simulations are given in Table 2. Note that the temporal resolution here does not refer to an average but an instantaneous value every $30 \mathrm{~min}$.

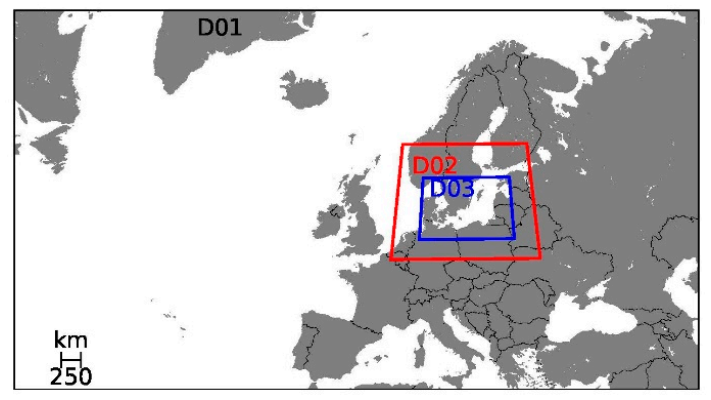

Figure 8. Model domains of WRF runs used for comparison.

Table 2. Details of WRF simulations.

\begin{tabular}{ll}
\hline WRF Model Version & 3.8 .1 \\
\hline Atmospheric Boundary Condition & ERA Interim [25] \\
\hline Sea Surface Temperatures & OSTIA [26] \\
\hline Land Use Data & USGS \\
\hline Horizontal Resolution & D01 (27 km), D02 (9 km), D03 (3 km) \\
\hline Nesting & 1-way \\
\hline Vertical Resolution & 62 levels-with 20 below $1000 \mathrm{~m}$ \\
\hline Microphysics & WSM 5-class scheme \\
\hline Planetary Boundary Layer Scheme (PBL) Scheme & MYNN (Level 2.5) \\
\hline
\end{tabular}

In order to compare the ship lidar measurements with the WRF simulations, the measurement data are mapped onto the WRF grid, and for each 10-min interval, the "closest" WRF output value was selected. For a further description of this mapping procedure see Reference [27].

Figure 9 shows the results of the comparison for the period already referred to in the preceding data plots. The mesoscale data were interpolated from the terrain following the hybrid pressure coordinates to $100 \mathrm{~m}$ at every time step. Both for the horizontal wind speed and direction, the two time series showed a very similar course. Deviations seem to be in the order of, and not larger than, the scatter, i.e., the deviations between individual data points, in typical WRF-to-met-mast comparisons offshore [9]. 
Larger deviations are observed for the periods where the ship lies in the harbor (cf. also Figure 5) and could easily be explained by the existence of relevant microscale effects that are not included in the mesoscale model. Further offshore these effects are obviously negligible.
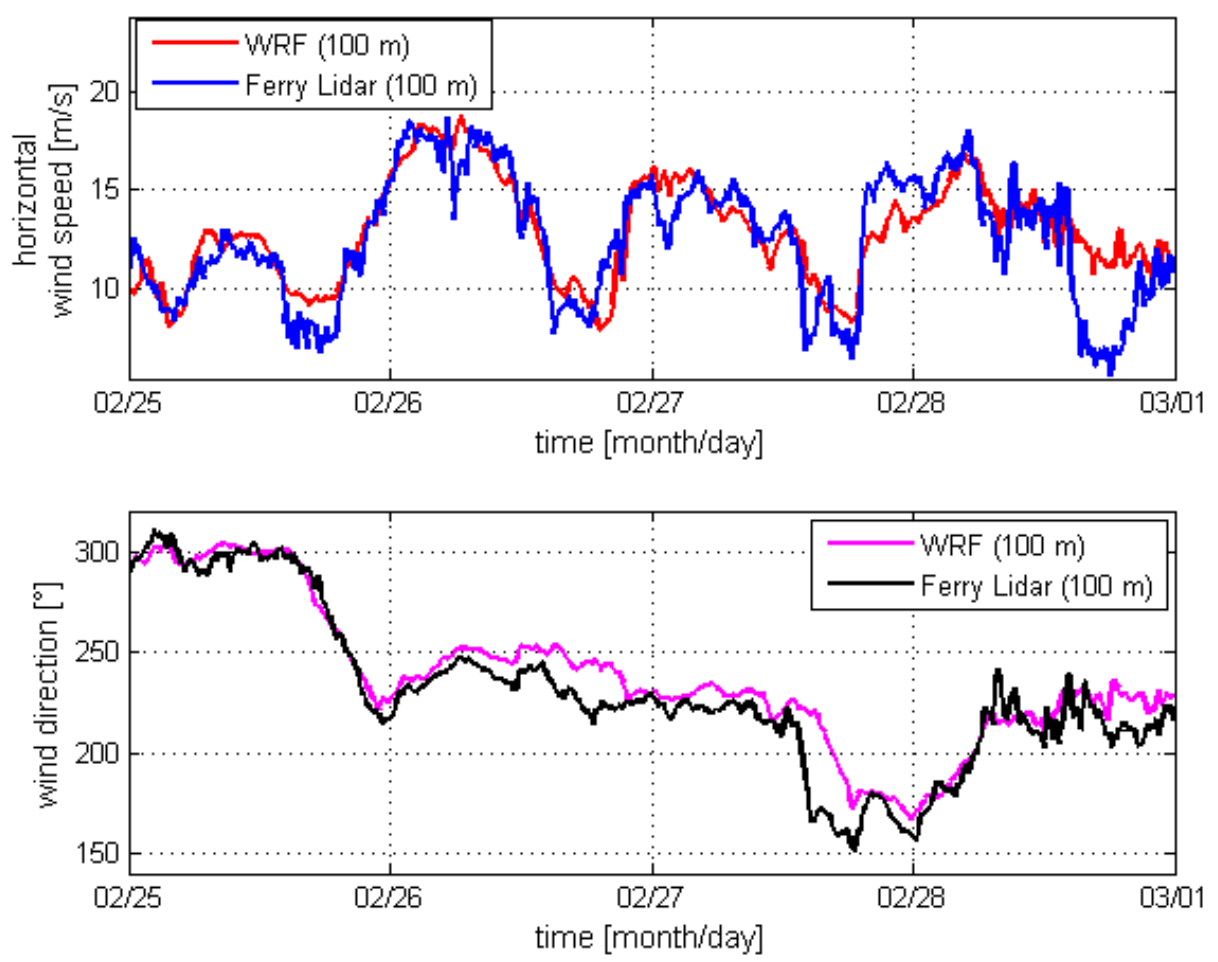

Figure 9. Comparison of the measured and simulated (Ferry Lidar vs. WRF) time series of horizontal wind speed and direction, here for $100 \mathrm{~m}$ measurement height only.

To further quantify the observed deviations, we have derived bias and root-mean-square-error (RMSE) values for the deviations in horizontal wind speed and wind direction between the Ferry Lidar and WRF data (see Table 3). For this evaluation, the "harbor effects" were excluded by considering only the data with a longitude coordinate larger than $10.4^{\circ}$ and below $20.0^{\circ}$.

The comparison indicates that the 4-day period selected for demonstration indeed shows a better performance than the overall dataset. A deeper analysis may reveal that the agreement varies with the location of the measurement in combination with the wind direction due to the prevailing site effects that were existent at some locations over the track. A corresponding filtering should be applied when further working with the dataset and, in particular, when setting up a benchmark study.

Table 3. Bias and RMSE values for the deviations in horizontal wind speed and wind direction between the Ferry Lidar and WRF data.

\begin{tabular}{ccccc}
\hline & \multicolumn{2}{c}{ Horizontal Wind Speed $[\mathrm{m} / \mathrm{s}]$} & Wind Direction $\left[{ }^{\circ}\right]$ \\
\cline { 2 - 5 } & 4-Day Period (25-28 February 2017) & All Data & 4-Day Period (25-28 February 2017) & All Data \\
\hline Bias & 0.09 & 0.35 & -5.2 & -6.3 \\
\hline RMSE & 1.31 & 1.90 & 8.3 & 29.2 \\
\hline
\end{tabular}

\section{Outlook}

First comparisons show a good correlation of the measurement data from the NEWA Ferry Lidar Experiment recorded using a ship-mounted lidar device with mesoscale model data simulated using the WRF model and mapped onto the ship's route in time and space. This opens up promising possibilities, overcoming the difficulty of verifying mesoscale model output data against in-situ data of, e.g., met masts that represent a very small and fixed volume only. Data of a ship lidar system 
could instead be representative of a line covering a certain space that is similar to the resolution of a mesoscale model simulation for a respective time scale. Comparing the time series of an NWP model with the data trajectories of the measurement system moving in space, and finding good correlations, may increase the trust in the model data and further promote their use as primary data for a wind resource assessment where on-site measurements are otherwise challenging. Studying the correlations between the two data sources along well-defined tracks may help to assess and understand where NWP models show larger and possibly systematic discrepancies.

The comparisons presented in this contribution represent only a first step. Within the NEWA project, the data of the Ferry Lidar Experiment are provided as a basis for more detailed benchmark studies that are planned and currently prepared for the near future. Furthermore, apart from that, the measurement data are part of the open accessibly NEWA Experimental Database, which will be available to the broader public for manifold investigations after the end of project, i.e., from May 2019.

\section{Conclusions}

The article presents the Ferry Lidar Experiment conducted within the NEWA project from February to June 2017. It introduces the ship lidar technology, which was applied on a ferry route from Kiel to Klaipeda in the Southern Baltic Sea. The obtained dataset of measurements is described in detail and made comprehensible. It is discussed how the data differ from met mast measurements as typical on-site data used for wind resource assessments in the wind industry. Ship lidar data stand out due to their covering of the detailed wind profile with a good data availability of more than $80 \%$ for measurement heights up to $175 \mathrm{~m}$ and still a reasonable availability (above 50\%) for heights up to 250 m. From this data basis, e.g., low level jet information can be derived.

Measured wind time series are further compared to output data of an NWP model. The results of this initial comparison demonstrate that mesoscale simulations with their domain sizes in the order of the ship track, i.e., the distance the ship covers in the applied averaging period of 10 min, compare well to the ship lidar measurements.

To our knowledge, the NEWA Ferry Lidar Experiment provides the first dataset of wind profile measurements using lidar technology covering wind-energy relevant scales along a track of that length and distance (i.e., several hundreds of kilometers).

Author Contributions: J.G. prepared the original draft and managed the measurement campaign. E.C. developed and performed the data analysis and produced most of the results. M.D. provided the simulated data and contributed in numerous discussions. B.W. contributed in numerous discussions and supported the interpretation of the results. All authors reviewed and edited the manuscript until it reached the final stage.

Funding: This research: as part of the NEWA project, was funded by the German Federal Ministry for Economic Affairs and Energy (ref. no. 0325832A/B) on the basis of a decision by the German Bundestag with further financial support from NEWA ERA-NET Plus, topic FP7-ENERGY.2013.10.1.2.

Acknowledgments: The authors would like to acknowledge the contribution of DFDS, for giving us access to the Victoria Seaways and supporting the measurement campaign. Special thanks go to Gerrit Wolken-Möhlmann for his comments to the manuscript and his great efforts in developing and demonstrating the Ship Lidar technology in earlier studies as the ones referred to in the article. The presented simulations were performed at the HPC Cluster EDDY, located at the University of Oldenburg (Germany) and funded by the BMWi (ref. no. 0324005).

Conflicts of Interest: The authors declare no conflict of interest.

\section{References}

1. Petersen, E.L.; Troen, I.; Jørgensen, H.E.; Mann, J. Are local wind power resources well estimated? Environ. Res. Lett. 2013, 8, 011005. [CrossRef]

2. Mann, J.; Angelou, N.; Arnqvist, J.; Callies, D.; Cantero, E.; Chávez Arroyo, R.; Courtney, M.; Cuxart, J.; Dellwik, E.; Gottschall, J.; et al. Complex terrain experiments in the New European Wind Atlas. Philos. Trans. A Math. Phys. Eng. Sci. 2017, 375, 20160101. [CrossRef] [PubMed] 
3. Peña, A.; Hasager, C.B.; Badger, M.; Barthelmie, R.J.; Bingöl, F.; Cariou, J.-P.; Emeis, S.; Frandsen, S.T.; Harris, M.; Karagali, I.; et al. Remote Sensing for Wind Energy, DTU Wind Energy-E-Report-0084 (EN). 2015. Available online: http:/ / orbit.dtu.dk/files/111814239/DTU_Wind_Energy_Report_E_0084.pdf (accessed on 31 August 2018).

4. Witze, A. World's largest wind-mapping project spins up in Portugal. Nature 2017, 542, 282-283. [CrossRef] [PubMed]

5. Floors, R.; Pena, A.; Lea, G.; Vasiljevic, N.; Simon, E.; Courtney, M. The RUNE Experiment-A Database of Remote-Sensing Observations of Near-Shore Winds. Remote Sens. 2016, 8, 884. [CrossRef]

6. Lange, B.; Larsen, S.; Hojstrup, J.; Barthelmie, R. Importance of thermal effects and sea surface roughness for offshore wind resource assessment. J. Wind Eng. Ind. Aerod. 2004, 92, 959-988. [CrossRef]

7. Hahmann, A.; Witha, B.; Sile, T.; Dörenkämper, M.; Söderberg, S.; Navarro, J.; Leroy, G.; Folch, A.; Garcia Bustamante, E.; Gonzalez-Rouco, F. WRF sensitivity experiments for the mesoscale NEWA wind atlas production run. In Proceedings of the European Geosciences Union (EGU) General Assembly, Vienna, Austria, 8-13 April 2018.

8. Jimenez, B.; Durante, F.; Lange, B.; Kreutzer, T.; Tambke, J. Offshore Wind Resource Assessment with WAsP and MM5: Comparative Study for the German Bight. Wind Energy 2007, 10, 121-134. [CrossRef]

9. Olsen, B.T.; Hahmann, A.N.; Sempreviva, A.M.; Badger, J.; Jørgensen, H.E. An intercomparison of mesoscale models at simple sites for wind energy applications. Wind Energy Sci. 2017, 2, 211-228. [CrossRef]

10. Information on the NORSEWInD Project. Available online: http://www.norsewind.eu/norse/index.php (accessed on 29 August 2018).

11. Wolken-Möhlmann, G.; Gottschall, J.; Lange, B. First verification test and wake measurement results using a Ship-LIDAR System. Energy Procedia 2014, 53, 146-155. [CrossRef]

12. Edson, J.B.; Hinton, A.A.; Prada, K.E.; Hare, J.E.; Fairall, C.W. Direct covariance flux estimates from mobile platforms at sea. J. Atmos. Ocean. Technol. 1998, 15, 547-562. [CrossRef]

13. Strobach, E.J. The Impact of Coastal Terrain on Offshore Wind and Implications for Offshore Wind Energy. Ph.D. Thesis, University of Maryland, Baltimore, MD, USA, 2017.

14. Gottschall, J.; Gribben, B.; Stein, D.; Würth, I. Floating lidar as an advanced offshore wind speed measurement technique: Current technology status and gap analysis in regard to full maturity. WIREs Energy Environ. 2017, 6, e250. [CrossRef]

15. Karagali, I.; Hasager, C.; Badger, M.; Hahmann, A.; Volker, P.; Pena, A.; Gottschall, J.; Catalano, E.; Mann, J. Mapping offshore winds in the New European Wind Atlas. In Proceedings of the Offshore Wind Energy Conference, London, UK, 6-8 June 2017.

16. Peña, A.; Gryning, S.E.; Hasager, C.B. Measurements and Modelling of the Wind Speed Profile in the Marine Atmospheric Boundary Layer. Bound.-Layer Meteorol. 2008, 129, 479-495. [CrossRef]

17. Tambke, J.; Claveri, L.; Bye, J.A.; Poppinga, C.; Lange, B.; Bremen, L.V.; Durante, F.; Wolff, J.O. Offshore Meteorology for Multi-Mega-Watt Turbines. In Proceedings of the European Wind Energy Conference (EWEC), Athens, Greece, 27 February-2 March 2006.

18. Baas, P.; Bosveld, F.C.; Klein Baltink, H.; Holtslag, A.A.M. A Climatology of Nocturnal Low-Level Jets at Cabauw. J. Appl. Meteorol. Climatol. 2009, 48, 1627. [CrossRef]

19. Emeis, S. Wind Energy Meteorology: Atmospheric Physics for Wind Power Generation, 2nd ed.; Springer International Publishing: Cham, Switzerland, 2018; 255p.

20. Smedman, A.-S.; Högström, U.; Bergström, H. Low Level Jets-A Decisive Factor for Off-Shore Wind Energy Siting in the Baltic Sea. Wind Eng. 1996, 20, 137-147.

21. IEC 61400-12-1:2017 (International Standard). Wind Energy Generation Systems_Part 12-1: Power Performance Measurements of Electricity Producing Wind Turbines; IEC: Geneva, Switzerland, 2017.

22. WMO (World Meteorological Organization). Guide to Meteorological Instruments and Methods of Observation (CIMO guide) No. 8 (2014 edition, updated in 2017). Available online: http:/ / www.wmo.int/ pages/prog/www/IMOP/CIMO-Guide.html (accessed on 11 October 2018).

23. Skamarock, W.C.; Klemp, J.B.; Dudhia, J.; Gill, D.O.; Barker, D.M.; Duda, M.G.; Huang, X.Y.; Wang, W.; Powers, J.G. A Description of the Advanced Research WRF Version 3; Technical Report NCAR/TN-475+STR; NCAR—National Center for Atmospheric Research: Boulder, CO, USA, 2008. 
24. Dörenkämper, M.; Optis, M.; Monahan, A.; Steinfeld, G. On the offshore advection of boundary-layer structures and the influence on offshore wind conditions. Bound.-Layer Meteorol. 2015, 155, 459-482. [CrossRef]

25. Dee, D.P.; Uppala, S.M.; Simmons, A.J.; Berrisford, P.; Poli, P.; Kobayashi, S.; Andrae, U.; Balmaseda, M.A.; Balsamo, G.; Bauer, D.P.; et al. The ERA-Interim reanalysis: Configuration and performance of the data assimilation system. Q. J. R. Meteorol. Soc. 2011, 137, 553-597. [CrossRef]

26. Donlon, C.J.; Martin, M.; Stark, J.; Roberts-Jones, J.; Fiedler, E.; Wimmer, W. The Operational Sea Surface Temperature and Sea Ice Analysis (OSTIA) system. Remote Sens. Environ. 2012, 116, 140-158. [CrossRef]

27. Catalano, E. Assessment of Offshore Wind Resources through Measurements from a Ship-Based LiDAR System. Master's Thesis, Genova University, Genova, Italy, 2017.

2018 by the authors. Licensee MDPI, Basel, Switzerland. This article is an open access article distributed under the terms and conditions of the Creative Commons Attribution (CC BY) license (http://creativecommons.org/licenses/by/4.0/). 